\title{
Family Stories and Family Secrets
}

\section{ROBYN FIVUSH, HELENA MCANALLY AND ELAINE REESE}

\begin{abstract}
Families preserve and rewrite history in ways that pass on to the next generation a sense of family history based on what is known and what cannot be told. In this paper, we analyze New Zealand European adolescents' stories about their parents' childhood, exploring how these young people tell and do not tell family stories shrouded in secrecy. We identify three major ways in which families express secrets across the generations - through collusion, through confusion, and through whole-family secrets - and discuss the implications of each of these family practices for the preservation of family history.
\end{abstract}

Families are both the heart of intimacy and the place of complex secrets. Families preserve and rewrite history in ways that pass on to the next generation a sense of family and individual identity based on what is known and what cannot be told, whether through silence, innuendo or evasion. ${ }^{1}$ This seeming paradox makes sense to all of us having grown up in a family, as well as to researchers who study family storytelling. Family is constituted, reconstituted and displayed through storytelling, stories of momentous occasions, births, deaths, marriages, as well as everyday occurrences, the small experiences that bond us together through time. ${ }^{2}$ But what happens when stories are not told, when secrets are kept and silence and innuendo is the only way through which certain events become known?

In this study, we examine a corpus of intergenerational narratives, stories passed on from the older generations to the younger generation, and how family secrets may be communicated in these stories, creating spaces and moments of uncertainty, what Smart labels "veils of confusion." 3 We focus on narratives solicited from New Zealand adolescents participating in a larger study of narrative identity, and we ask how these young people tell and do not tell family stories shrouded in secrecy, and why this matters for understanding how family histories may be passed down to the next generations. New Zealand presents a particularly interesting culture to study given the historical context of the era in which these adolescents' parents were growing up. Post-war New Zealand was a period that featured early marriage, large families, high infant mortality rates, high rates of illegitimate births and no access to legal abortions, closed adoptions and relatively authoritarian parenting styles by international standards. ${ }^{4}$ It was also a period of rapid social change, in the 1960s and 1970s, with the advent of widespread birth control and the women's movement, both of which contributed to intrafamilial and intergenerational strife in a largely conservative political climate. ${ }^{5}$ Thus, current New Zealand adolescents have parents who likely experienced a great deal of social change and intergenerational conflict.

We begin by explicating the critical role of family stories in creating both family history and individual identity, before delving more deeply into how family secrets may impact on this process. We then turn to our focus on New Zealand adolescents, providing theoretical motivation for studying this group of young people as they navigate towards an adult identity. We identify

Journal of New Zealand Studies NS29 (2019), 20-36 https://doi.org/10.26686/jnzs.v0iNS29.6259 
three major ways in which families express secrets across the generations-through collusion, through confusion, and through whole-family secrets - and discuss the implications of each of these family practices for the preservation of family history.

\section{Family Storytelling in Creating Family History and Personal Identity}

Infants are born into storied worlds. Parents and grandparents whisper stories of who this new one is and the family they were born into to soothe and comfort. ${ }^{6}$ As children grow older, they are expected to participate in asking, telling and ingesting family stories, becoming a part of this family through becoming a part of the stories and the tellings. ${ }^{7}$ These stories span telling about experiences of the generational family, events that happened that day or last year, as well as of the intergenerational family, stories of the parents when they were growing up, of grandparents, aunts and uncles, of forebears and their lives, their struggles and triumphs. All of these stories are interleaved in everyday family interactions, where stories emerge just about every five minutes in typical family conversations, ${ }^{8}$ and are internalized as part of each family member's own life story. ${ }^{9}$ This may be particularly important during adolescence, when individuals are challenged to construct a healthy adult identity. We can see this process at work in this narrative from a 14-yearold girl whom we will call Virginia. Virginia participated in a larger study exploring both personal narratives and family narratives. During one of four home visits, a female interviewer asked Virginia for stories she might know about her mother and her father when they were growing up. This is a story Virginia said she was told by her mother about her mother's childhood, a story that is clearly placed in a particular historical moment in US history:

she was born in [name of US southern city] and um she didn't go to school or anything until she was ... until they moved to [name of second southern city]. But, in [city she was born in], she was raised pretty much by their housekeeper, Debbie and uh my mom loved Debbie. Um . . . Like Debbie would braid her hair and give her cornrows and stuff ... and when they ... they moved to [name of second southern city] after that and they left Debbie behind and my mom was really upset. And my grandparents I guess just thought that it was because you know they were moving and she didn't want to leave her home behind, but really it was because she really loved Debbie; she was like a mother to her. And um and she didn't want to leave her behind. So she started school, first grade... Debbie was African-American and she had always played with Debbie's kids and um, you know, other African-American kids, so when she first got to her school ... she'd never been to school before and all the schools were newly . . . integrated. So, you know, of course, there was still a lot of changing between the races, so my mom automatically just kind of drifted towards the African-American kids 'cause that's who she had um been raised ... raised around. So um ... and no one ... it didn't really go over very well with ... with the white children. Um and I think I recall her saying that like they called her like a "N-word lover" and stuff like that and just really terrible things. So, but, you know. ... And she had no idea. I mean I don't think she even knew about any type of racial discrimination. So like that was a really big shock for her.

[Interviewer asks: And what did you learn from that story?]

Um ... I learned that we aren't born with prejudices and stuff; it's those are things that are learned by um ... things you just kind of pick up I guess from your environment. 
This story is placed in historical context, the period of integrating schools in the southern US, in family context, the family moving from one city to another, and in Virginia's mother's life context, explicitly narrating not just the event but her mother's thoughts and emotions, her intentions and motivations, and, perhaps most important, the lessons learned from this event and how it has shaped Virginia's own understanding of race relations. The story situates Virginia within a specific family context, from grandparents to parents to self, that defines Virginia's place in the world as well as her beliefs and values. This kind of family storytelling across the generations is what Assmann and Czaplicka describe as "communicative memory." 10 Stories told by grandparents and parents to the younger generations are critical for passing down information that may otherwise remain undocumented. Virginia's story of her mother goes beyond the fact of racial discrimination to describe a deeply embodied and emotional experience that provides a compelling context for understanding a particular historical perspective. Without these fleshed out stories that bring specific facts to life, they are merely words on paper, and cannot carry the immediacy or intimacy of a personal story in ways that connect individuals across the generations. Although current genealogical tools, such as web-based archives, may provide more and easier access to family history and even detailed family documents, we argue that the ability to engage in storytelling with another living person over extended periods of time builds a kind of relationship and intimacy that is not possible outside of this type of temporally extended communication. For the younger generation, being an integral and integrated part of the storytelling experience creates a sense of intimate family bonding that is different than unembodied stories. ${ }^{11}$

Indeed, adolescents, both in the US and in New Zealand, who know more about their intergenerational past, and who tell stories about their parents growing up that are more elaborated and emotionally expressive, show higher levels of well-being, fewer behavior problems, and a greater sense of meaning and purpose in their own lives. ${ }^{12}$ Participating in family storytelling has a positive impact on adolescents' developing sense of who they are in the world. Family storytelling also has positive associations for the older generation. Grandparents and parents who participate in intergenerational storytelling with their families report a higher sense of meaning and purpose in their lives and report higher levels of generativity, a sense of leaving a legacy for the next generation. ${ }^{13}$ Family storytelling is good for individuals.

Family storytelling is also good for preserving family history and family identity. Family storytelling creates a sense of intimacy among family members that bonds them together through time. ${ }^{14}$ Importantly, family storytelling creates a constellation of privileged knowledge among family members, a sense that they know each other better than anyone else knows them, often codified in winks and glances, but also in stories. ${ }^{15}$ The stories that are told and retold at every family holiday become touchstones, ways of quickly establishing or reestablishing connections between and among family members. These stories provide maps to understanding how the world does work and how it should work, and express core values and ideals. ${ }^{16}$ Family stories are not just about preserving history, but about creating family futures that uphold and honor what the family has experienced.

Critically, it is not only positive experiences that create this sense of enduring family. In fact, difficult and challenging experiences may be even more important for creating a sense of resilience

Journal of New Zealand Studies NS29 (2019), 20-36 https://doi.org/10.26686/jnzs.v0iNS29.6259 
and perseverance in the face of challenge. ${ }^{17}$ Families that share their challenging and stressful experiences through story, especially stories of overcoming and enduring in the face of these challenges, have adolescents that show higher levels of self-esteem and self-efficacy. ${ }^{18}$ But, obviously, not all difficult and challenging stories are explicitly told. Every family has stories that remain hidden or incompletely conveyed. Yet many of these stories are still somehow expressed and passed down through the generations. How are secrets shared and not shared, heard and not heard, told and not told? And why might this matter?

\section{Family Secrets}

Every family has its secrets, some hidden so deeply that they become lost to history, others openly known among all family members but simply never talked about. Secrets can bond families together or damage family relationships. ${ }^{19}$ Families are obviously complex and multifaceted, with many people across long time periods together creating an evolving story of family identity. The stories that families tell are as much about who we want to be as who we are; family stories embrace how families imagine themselves, ${ }^{20}$ and much of this revolves around how families and relationships are constituted. These types of stories therefore often circle around the configuration of the family — births, marriages, affairs, deaths ${ }^{21}$ —or relationships and events within the familyabuse, alcoholism ${ }^{22}$ - that break with the idealized image of what a family should be.

Various researchers have described different forms or types of family secrets. Within the social sciences, Vangelisti systematically surveyed the frequency and types of secrets families keep. ${ }^{23}$ She distinguishes between intrafamily secrets, secrets that some family members know but keep from other family members, and whole-family secrets, secrets known by the entire family but never shared with outsiders. The former almost always leads to a sense of insecurity and betrayal, a sense of alliances within the family; who is allowed to know what, and when, become difficult negotiations. Paradoxically, the latter can actually bond family members together and create intimacy, in the sense of belonging to an in-group. But this is not always the case. Some wholefamily secrets are insidious, in that children are socialized not to reveal information damaging to the family and as a result suffer anxiety and depression. ${ }^{24}$ Some family secrets are kept for political and/or economic purposes. For example, Barnwell describes how certain family stories are camouflaged to hide the horrific maltreatment perpetuated by Australian settlers on the indigenous population, ${ }^{25}$ and Welzer and colleagues discuss how Nazi soldiers hid their war activities from their children and grandchildren. ${ }^{26}$ These kinds of family secrets create a veil across history itself. In a more individualized way, Goodall describes his father's work as a professional spy for the US CIA as a toxic secret that essentially destroyed the father-son relationship, ${ }^{27}$ and McNay discusses how she learned about her father's childhood as a "home child," essentially an indentured childhood on a Canadian farm, from her mother, who told her only "Your dad had a hard life."28 Similar stories appear in New Zealand cultures. For instance, New Zealand author Greg McKee reveals a family secret of the kidnapping of his father and uncles by their grandfather after the death of their mother ${ }^{29}$; McKee's great-grandfather had nine daughters and wanted sons to work on his farm. As a consequence, McKee's father never knew his father. This family story has formed the basis for a recent work of fiction by the author. These allusions to difficult experiences may leave younger family members unnerved, and unanchored without the story that elaborates and explains how the parent became the person they are and why they behave the way they do. Whereas

Journal of New Zealand Studies NS29 (2019), 20-36 https://doi.org/10.26686/jnzs.v0iNS29.6259 
stories of difficult and challenging events can create empathy and connection, when these stories are shrouded in secrecy they can lead to confusion and even shame.

\section{The Current Study}

Theory and limited research on family secrets suggest that the ways in which families do and do not share difficult experiences across the generations has effects on the individual children, family relations, and, ultimately, on how family history may or may not be preserved. Additionally, theorists posit that these kinds of experiences are transmitted in everyday conversations, whether openly or through silence, innuendo or confusion. Yet there is little research that examines how and what is actually communicated in everyday family conversations. We were in a position to begin to explore this question through a corpus of data collected between 2009 and 2011 from 270 adolescents between the ages of 12 and 21 living in New Zealand whose parents had grown up in post-war New Zealand in the thick of the baby boom. ${ }^{30}$ The full data collection included adolescents who self-identified as New Zealand Chinese, Māori, or European, but for the purposes of this study, we focused on the 91 adolescents, 45 girls and 46 boys, who identified themselves as New Zealand European in the recruitment process. All were attending secondary or tertiary education in a small city in New Zealand. The data, collected by the second and third authors, is part of a larger longitudinal study examining multiple aspects of family reminiscing and adolescents' personal narratives. As part of this data collection, adolescents were asked to tell stories they might know about their parents' childhoods. More specifically, researchers asked the following:

Up to now we've been talking about your life, but now I'd like to hear a little bit about your parents' lives, in particular the stories that you might know about your mum and dad when they were kids. So these are not experiences that you remember, but stories that you might have been told. Can you tell me a story that you know about your mum (dad) when she (he) was a kid?

Adolscents were prompted with "Anything else?" until they indicated there was no more to tell. The interviewer then asked the adolescent how they knew this story and who had told them. Interviews were conducted in a family study area at the university lab by a female interviewer (the second author) who was trained to follow a specific interview protocol that first asked adolescents to tell about their own life story, including their earliest memory and significant events (adapted from "The Life Story Interview" ${ }^{31}$ ). All oral interviews were transcribed verbatim.

We focused on this age group in particular because adolescence and early adulthood represents a transition both in individual development and in terms of family history and future. It is a period characterized by developmental changes that include the ability to think in a more abstract way and to negotiate the ability to hold many roles or experiment with different identity affiliations. Perhaps as a consequence of this, it is also a time adolescents start to understand their parents as people rather than just authority figures. ${ }^{32}$ This broadened perspective on their parents may be one reason why family stories are often elicited by adolescents $(65 / 270$ or 24 percent in the larger corpus reported the reason they were told this story was "because I asked"33). Eliciting family stories, particularly painful ones, may reflect adolescents' attempts to negotiate a more mature 
relationship with their parents, one based on mutual care, respect and understanding rather than simpler roles of "child" and "parent."

We further chose to conduct a within-culture analysis of the New Zealand European adolescents' intergenerational narratives, primarily for pragmatic reasons given the number of narratives in the larger sample. We plan to undertake similar within-culture analyses of the New Zealand Chinese and Māori narratives in the future, in collaboration with the interviewers for those cultures.

\section{Methodological Approach}

As developmental psychologists, our research focuses on processes of change over time within an individual's lifetime, and especially in the first two decades of life, as children develop from infancy to adulthood within family systems. We have done extensive work with families studying patterns of reminiscing about the generational past, experiences between parents and children living in the same household, and how these reminiscing practices shape individual autobiography. ${ }^{34}$ Within this research program, it has become more and more obvious that when families talk about their shared past experiences, they also bring in the intergenerational past, referencing experiences from the parents' childhoods, grandparents and extended family members. Thus, our research focus has expanded to communicative memory practices, the ways in which the family shares the intergenerational past. ${ }^{35}$ Given our theoretical lens, we have been most interested in how individual memory is shaped by intergenerational communicative practices, and both individually and together we have studied the stories that families tell. As part of this process, we have become more intrigued by the stories that are not told, that are alluded to and/or silenced. Thus we come to this analysis with theoretical and methodological tools for analyzing family conversations about the past, but were additionally guided for this analysis specifically by the theoretical framework on family secrets emerging from sociology and oral history, as well as from psychology, described above.

In addition to our theoretical training, we come to this analysis from our own contextualized family histories. The first and third authors grew up in the US (the first author in New York City and the third author in Texas). The first author has spent a great deal of time in New Zealand as a visiting scholar during multiple academic sabbaticals, and the third author moved to New Zealand as a young adult, has lived in New Zealand for over 20 years, where her children were born and raised, and she is now a New Zealand citizen. The second author was born and raised in the same city as the adolescents in this study, and in fact attended the same secondary and tertiary institutions that the adolescents were attending when interviewed. Thus, the adolescents told their stories for an audience of an interested listener who was familiar with their cultural, social, and school contexts. ${ }^{36}$ Across the three of us, we bring elements of participant observers as well as members of the culture. In accordance with best practices for qualitative research, ${ }^{37}$ we strive to be as reflective as possible about how our own personal family experiences might colour the way in which we read and interpret these transcripts, but we acknowledge that this is a fraught process. We emphasize that all three of us independently read the transcripts and independently identified the same set of narratives to include in the analysis, and, with the exception of William's narrative described in detail below, all three of us independently agreed on interpretations of the narratives.

Journal of New Zealand Studies NS29 (2019), 20-36 https://doi.org/10.26686/jnzs.v0iNS29.6259 


\section{Identification of Transcripts for Analysis}

We began the project by independently iteratively reading all the intergenerational narratives in the corpus. We note that this is not actual observation of family communication per se, but rather the outcomes of these kinds of conversations. These are stories that adolescents can only know if they are told. The adolescents did not personally experience any of these events, but rather have heard stories from their families, usually their parents, about these experiences and what they mean. Following the elicitation of the narratives themselves, we asked follow-up questions about how the adolescent knew these stories, who told them and why they thought these stories were told. Thus we had a rich set of information about how families communicate about the intergenerational past, at least from the adolescents' perspective. We acknowledge that we have no independent information regarding either the occurrence of these experiences in the parents' lives nor the parents' perspectives on how these experiences have been communicated. Rather, in accord with best practices in thematic text analysis, we rely on the adolescent's telling as a way into examining how this event has been communicated. ${ }^{38}$

Through multiple readings, we identified narratives in which the adolescent referenced some form of secrecy surrounding the story, through explicit reference to silencing, through evasion or confusion. This occurred in a number of ways, including reference to the fact that the adolescent should not tell, or feels uncomfortable telling, someone outside the family, such as one adolescent who told us "Um, yeah, I'm not sure if I should tell you some of this though," or by explicitly referencing that they feel uncomfortable talking to someone inside the family about this event, as in an adolescent who said, "I've never brought it up with Nana. I never would."

Of the 91 total number of adolescents, 8 (or about 10 percent) referenced some form of secretive experiences. Of these 8 adolescents ( 6 girls and 2 boys of a total of 45 girls and 46 boys in the full NZ European sample), 6 told one such narrative about one of their parents ( 5 girls and 1 boy) and 2 told this kind of narrative about both parents ( 1 girl and 1 boy), yielding 10 narratives for analysis. Table 1 describes the types of events that these adolescents discussed in the order in which we present them in our analyses, along with their pseudonyms, their age, and the parent whom the event was about.

Table 1. Secretive Experiences Recounted during Interviews.

\begin{tabular}{|l|l|l|l|l|}
\hline Pseudonym & Parent & $\begin{array}{l}\text { Event } \\
\text { Type }\end{array}$ & Event description & $\begin{array}{l}\text { How the adolescent } \\
\text { knows the story }\end{array}$ \\
\hline $\begin{array}{l}\text { Mia } \\
\text { (age 19) }\end{array}$ & Mother & Death & Mother's mother had a stillbirth & $\begin{array}{l}\text { Mentioned only as a } \\
\text { background detail; no } \\
\text { additional information } \\
\text { given }\end{array}$ \\
\hline $\begin{array}{l}\text { Ella } \\
\text { (age 12) }\end{array}$ & Father & Abuse & Father's mother was alcoholic & Adolescent asked \\
\hline $\begin{array}{l}\text { Emily } \\
\text { (age 17) }\end{array}$ & Father & $\begin{array}{l}\text { Probable } \\
\text { abuse }\end{array}$ & $\begin{array}{l}\text { Father was probably abused } \\
\text { throughout childhood, or at }\end{array}$ & Mother told her \\
\hline
\end{tabular}

Journal of New Zealand Studies NS29 (2019), 20-36 https://doi.org/10.26686/jnzs.v0iNS29.6259 


\begin{tabular}{|l|l|l|l|l|}
\hline & & & $\begin{array}{l}\text { least experienced an extremely } \\
\text { authoritarian upbringing }\end{array}$ & \\
\hline $\begin{array}{l}\text { Ava } \\
\text { (age 13) }\end{array}$ & Father & Death & $\begin{array}{l}\text { Father's father died when } \\
\text { father was young }\end{array}$ & Adolescent asked \\
\hline $\begin{array}{l}\text { Mia } \\
\text { age 19) }\end{array}$ & Father & Abuse & $\begin{array}{l}\text { Father was abused throughout } \\
\text { childhood }\end{array}$ & Adolescent asked \\
\hline $\begin{array}{l}\text { Zachary } \\
\text { (age 20) }\end{array}$ & Mother & Paternity & $\begin{array}{l}\text { Mother's mother married } \\
\text { multiple times }\end{array}$ & Adolescent asked \\
\hline $\begin{array}{l}\text { Zachary } \\
\text { (age 20) }\end{array}$ & Father & Death & $\begin{array}{l}\text { Father's father died when } \\
\text { father was young }\end{array}$ & Adolescent asked \\
\hline $\begin{array}{l}\text { Amelia } \\
\text { age 12) }\end{array}$ & Mother & Abuse & $\begin{array}{l}\text { Mother thrown out of house } \\
\text { when pregnant as a teenager }\end{array}$ & $\begin{array}{l}\text { Unclear; adolescent } \\
\text { indicates she "always } \\
\text { knew" }\end{array}$ \\
\hline $\begin{array}{l}\text { Olivia } \\
\text { (age 15) }\end{array}$ & Mother & Abuse & $\begin{array}{l}\text { Mother thrown out of house } \\
\text { when pregnant as a teenager }\end{array}$ & $\begin{array}{l}\text { Unclear; adolescent } \\
\text { indicates she "always } \\
\text { knew" }\end{array}$ \\
\hline $\begin{array}{l}\text { William } \\
\text { (age 17) }\end{array}$ & Mother & Adoption & Mother adopted & $\begin{array}{l}\text { Unclear; adolescent } \\
\text { indicates he "always } \\
\text { knew" }\end{array}$ \\
\hline
\end{tabular}

We emphasize that these are the adolescents who selected to tell these kinds of stories during their interviews; there are most likely many more adolescents who have engaged in family conversations about secretive experiences and who did not choose to tell us about them during these interviews. And, of course, there are likely many adolescents whose families never divulged anything about well-kept family secrets. Thus this is a select group, and we cannot know exactly why these specific adolescents chose these experiences to narrate. More to the point, our objective was to provide a deep description of the ways in which families do and do not tell certain kinds of experiences in ways that create family histories that may be secretive, evasive or confused. Thus our goal was not to determine the extent to which families engage in this practice, but rather to describe the ways in which families may do this. We note, however, the fact that even a small percentage of adolescents in a community sample expressed some form of secrecy suggests that they are not uncommon in everyday family experiences.

\section{Description of the Family Narratives}

Of the ten narratives selected for thematic analysis, seven were told by girls, three about their mother's childhood experiences and four about their father's childhood experiences. Only two boys expressed some form of secrecy: Zachary told confused and secretive narratives about both his mother and father, and William told a story about his mother being adopted. All three coders independently agreed that nine of these narratives expressed some form of secrecy, but there was disagreement about William's narrative that engendered a great deal of discussion among us, and that we think illuminates some intriguing aspects of how family secrets may or may not be defined. Thus we discuss William's narrative in some detail below. We also note Amelia and Olivia are sisters, and, in independent interviews, both elected to tell a narrative about their mother getting pregnant as a teenager and being kicked out of her house. Again, because they were sisters, they

Journal of New Zealand Studies NS29 (2019), 20-36 https://doi.org/10.26686/jnzs.v0iNS29.6259 
present an interesting case example of if and how difficult parental experiences may be communicated in secretive ways. Thus, as we identified and reread these narratives, we saw some provocative similarities and differences among them that illuminated specific themes for additional analysis.

In terms of general patterns, first, girls were more likely than boys to reference something about family secrets. Girls were about equally likely to reference such events about their mothers' childhoods as their fathers', whereas patterns for boys obviously cannot be ascertained. Second, the types of events that adolescents selected to discuss were consistent and limited in type, especially for the girls. Three of the narratives were about the parent experiencing the death of either their parent or a sibling during childhood, and 5 were about some form of abusive experiences during the parents' childhood. In addition, Zachary, who told about a death in his father's childhood, also told a confusing narrative about his grandmother being married multiple times that called into question issues of paternity and kinship, including his relationship to a woman he thought was his mother's aunt but was possibly her sister. It was unclear whether any of this information was a secret or simply poorly understood by Zachary. Similarly, William talked about his mother being adopted, but, again, there was some question over whether this was actually a secretive event at all.

Importantly, while many of these more secretive events can be considered traumatic for the parent, these were not the only adolescents who told narratives about parental trauma. An additional 13 adolescents ( 8 girls and 5 boys) narrated stories about a traumatic event in the parent's childhood: 7 about the death of the parent's parent or sibling, 3 serious accidents, and 2 stories about fleeing eastern Europe after the war. Thus it is not the case that stories about parental trauma are always or perhaps even often shrouded in secrecy. Whereas not all traumatic parental experiences are secretive, the patterns suggest that those that do become secretive may be similar in theme, in that they focus on births, deaths and marriages, events that configure the family structure. That childhood abuse is also often kept secret from the next generation expands previous findings about the insidious ways in which abuse within the family disrupts relationships across generations. ${ }^{39}$ In addition, the gender patterns mirror findings in the literature that indicate that adolescent girls know more of their family history than do adolescent boys. ${ }^{40}$ Both for events told, and perhaps for those not told, gender differences suggest that girls are the recipients of family history as well as the keeper of family secrets to a greater extent than are boys.

To begin to understand how families may or may not communicate secrets across the generations, we reread these 10 narratives multiple times in depth, with an eye towards systematically describing if and how these experience were discussed. Three overall categories emerged: withinfamily secrets expressed through collusion; within-family secrets expressed through confusion; and whole-family secrets.

\section{Within-Family Secrets: Collusion}

Within-family secrets are stories in which the adolescent communicates that this event is not talked about within the family, and, often, is explicitly not talked about with particular family members. Four narratives expressed within-family secrets, all of them by girls (three about the father and one about the maternal grandmother). Mia tells about her mother's mother having a stillborn child,

Journal of New Zealand Studies NS29 (2019), 20-36 https://doi.org/10.26686/jnzs.v0iNS29.6259 
but says, "that's never been talked about at all in our family." In fact, this information is only provided as background to the actual narrative that she does tell about her mother's adolescence, and so we have no information about how Mia knows this or who told her. She does say "I've never brought it up with Nana [the woman who had the stillbirth] and I never would." So there is a clear indication that this is a "known secret" in the sense that Mia is quite forthcoming with the information, and seems to know a lot of details, but is also quite clear that it is not discussed and certainly Mia avoids talking about it with the woman who experienced the traumatic event.

Three of the within-family secret narratives were ones for which the adolescent knew very little about the event, the event was really only vaguely acknowledged, and the narrative only known because the adolescent asked. All three involved the mother telling the daughter something about the father that appeared not to be discussed with the father. Two were about the fathers' abusive childhood. Ella's father's mother was an alcoholic, and, in Ella's words, "that's all I really know," although she does provide one horrible detail about her father's abuse (not revealed here to insure anonymity). Ella was told by her mother because she kept asking questions; in Ella's telling of this conversation it seems her mother made clear that that was all there was to tell and no more questions should be asked. Similarly, Emily's father's father was "very strict," and her mother told her this to help her understand "why he brought some of his problems to our family" and "to try to help me understand why he is the way he is." Clearly, Emily has a difficult relationship with her father and the mother is trying to help her daughter understand why this might be without revealing any details. The third narrative of this type is Ava's, who tells that her father's father died when her father was very young, and "that's all I really know." Again, it was her mother who told her, not her father, and only because Ava asked questions. In all three narratives, there is a sense that the mother and daughter are in collusion in sharing a secret, which perhaps is too painful to be openly discussed with the person the secret is about. In addition, the adolescent was only told about these experiences after repeated questioning, and is given the message that details are not forthcoming, the topic is closed. While these kinds of communications may help adolescents understand and empathize with their fathers, they still create a sense of "known secrets" within the family, things that are not to be discussed. These secrets may keep mother and daughter aligned, but they may also create problems in the broader family relationships.

That many family secret narratives present a sense of collusion with one parent seems to place the adolescent in a difficult emotional relationship with both parents, having to both know and not know something simultaneously. ${ }^{41}$ We can speculate that these kinds of stories might be carried forward in an emotionally negative way, communicating evasion and secrecy across the generations. Although stories of challenge often provide a foundation of family resilience and strength, when these stories are embedded in secrecy and evasion, this outcome is highly unlikely.

\section{Within-Family Secrets: Confusion}

Three of the within-family secretive narratives presented highly incoherent and confusing accounts. One of these was Mia's narrative about her father. Recall that Mia also mentioned a within-family secret about her grandmother's stillbirth. In the narrative about her father, Mia presents a long, very detailed but very confusing narrative about her father growing up in a community rife with episodes of violence and perhaps abuse. She claims that her father told her lots of stories, but when asked how she knows these stories, she responds that she had to ask a lot

Journal of New Zealand Studies NS29 (2019), 20-36 https://doi.org/10.26686/jnzs.v0iNS29.6259 
of questions and that he wouldn't talk about it. In her words, 'I've pestered them [her parents]. I'd never heard anything about it till I was a teenager. Um they never mentioned it when I was younger," and when her parents did tell her some stories, she said, "I was upset to the point of having to leave the conversation." She goes on to say, "I've also talked to Nanny about it. I've asked her ... she never really talks about it." So in the space of a short interview, Mia talks about how she was both told and how she was not told, how her father told her lots of stories, but her parents would not talk about it, nor would her father's mother. Although Mia does have details about her fathers' experiences, there is no coherent narrative to help place these upsetting experiences in any kind of context, nor is there any kind of closure, resolution or lesson learned.

The other two narratives that were incoherent and confused were both from Zachary, one about his mother and one about his father. Zachary starts his interview stating, "My parents are very reclusive." The narrative about his father is ostensibly about when his father's father died when his father was 13 years old, but the narrative moves back and forth among multiple unconnected unanchored details about the father's experiences of his childhood alongside comments about Zachary's own inability to remember what he may have been told, such as "I can't even remember" and "I just really didn't think. ..." When asked how he knows this, he responds that he asked his grandmother to tell him about his father, but then devolves into a narrative about his grandmother being in a nursing home. There are multiple references to who knows what and who knows who knows, as in "he [my father] doesn't know I know" and "I know a lot more than they would like to think I know about them." Zachary's narrative about his mother is just as confusing. He begins by saying, "my Mum's past is shrouded." He then provides a confusing incoherent narrative about either his mother and/or his grandmother being married multiple times, and therefore the family kinship system is essentially unknown. In his words, "It's just wacky but because of that I don't know much about my mother's fathers." It is not even clear who his mother's father actually was, or how many stepfathers she may have had. When asked how he knows, Zachary says his mother told him but only recently, and he is still trying to figure out how everyone is related to everyone else.

Because two of these highly incoherent and confusing narratives are told by the same adolescent, it is possible that this is just Zachary's narrative style. In previous portions of the interview when telling his own life story, Zachary was expressive, employing a sophisticated vocabulary and peppering his narratives with reported speech and curse words (Fan-f***ing-tastic!); at times, he was highly reflective about difficult personal events in his life. However, his overall narrative style was meandering, and his interview was one of the longest in the New Zealand European sample at nearly 13,000 words (5,000 words was the average length for New Zealand European participants). We know from a great deal of previous research that narrative coherence is socialized, ${ }^{42}$ and more specifically that the coherence of intergenerational narratives is related to the coherence of personal narratives. ${ }^{43}$ So even if this is Zachary's narrative style, it suggests a narrative socialization environment in which family storytelling more broadly is incoherent and confusing, and this is now reflected in Zachary's narratives. We also know that this kind of incoherence is related to lower levels of psychological well-being, including less of a sense of meaning and purpose in life and less positive personal relationships. ${ }^{44}$ Further, incoherent narratives are less likely to be recalled and retold than coherent narratives. ${ }^{45}$ This level of confusion 
in intergenerational narratives suggests less than optimal outcomes for either the adolescent or for the passing on of family history.

\section{Whole-Family Secrets}

Only two of the narratives expressed a sense that the whole family knew and acknowledged a particular event but were uncomfortable talking about it outside the family. Intriguingly, these were told by two sisters, Olivia, age 15, and Amelia, age 12, interviewed independently. Both chose to tell about their mother being kicked out of her house when she became pregnant as a teenager; it is important to our interpretation that their mother was pregnant with Olivia. Both sisters are remarkably consistent in expressing their discomfort in revealing this story. Olivia begins the interview with, "I'm not sure I should tell you some of this" and continues, "I don't know if I should say." Similarly, Amelia starts with, "Well, it's kinda, yeah, I don't, yeah . . OK, I'll just say it." Thus both indicate that this is an event that the family prefers to keep secret from outsiders. But they do diverge, in that Olivia further expresses that, although this event is openly acknowledged within the family, the family does not easily talk about it. Olivia simply says that her mother got kicked out of her house and then says she "can't remember anything" about the event, and when asked why she thinks her mother told her this event, she has no answer. She ends with "I just don't want to say much." There is a palpable sense of secrecy and even shame surrounding the entire experience for Olivia. In contrast, Amelia tells a full detailed narrative about what happened when her mother was kicked out of her house when pregnant, including that her mother's mother chased after her and brought her home, and how the parents and pregnant daughter all thought it over and started a new life together as a family. When asked why she thinks her mother told her this story, she responds, so that if this happens to her, her mother "won't kick me out or something. It's my choice." Although Amelia is also reticent to tell the interviewer, it is clear that Amelia feels that this experience is openly discussed among the family members, perhaps most especially between mother and daughter. In contrast to Olivia, Amelia does not express a sense of within-family secrecy or shame.

That two sisters growing up in the same house tell quite different narratives about what both agree is a whole-family secret presents some interesting questions about family secrets more broadly. We might have expected the older sister to communicate more than the younger sister, with the mother being more forthcoming with each of her daughters as they get older and come into their own sexual identity. That the younger daughter seems to know more, or at least be more open with strangers about discussing it, suggest two possibilities. One is that Amelia really does know more as the younger sister because the story has become more open over time as both daughters develop into their teenage years. The second possibility is that as the older sister develops into sexual maturity, the impact and meaning of the story becomes more powerful and perhaps more difficult, and therefore Olivia does not want to talk about it. This may be an especially difficult story for Olivia because it is her own birth story. Thus, she may be self-silencing. In any case, that Amelia does know so much suggests that the family may talk quite openly about this event, but both daughters clearly have gotten the message that this is not something to be discussed with outsiders. How this may play out in family history is unclear. Whole-family secrets may be passed down as lessons learned and/or as cautionary tales. What Amelia's and Olivia's interviews suggest is that even growing up in the same family, secrets may be communicated differently among different family members, perhaps depending on how those secrets impact on the individual. Thus the

Journal of New Zealand Studies NS29 (2019), 20-36 https://doi.org/10.26686/jnzs.v0iNS29.6259 
concept of "whole-family secret" is more complex in that there may be secrets within secrets within secrets.

\section{What are Family Secrets Anyway?}

Olivia and Amelia call into question how family secrets may be secretive, divulged, communicated in different ways even within the same family. William's narrative raises the question of what even might count as a family secret. We emphasize that we each read all 91 narratives independently and reached full agreement on both which narratives expressed a parental trauma and which narratives expressed some form of secrecy. In the entire corpus, there was only one narrative that presented us with a problem. This narrative, told by William about his mother being adopted, raised interesting questions about what it means to know and not know, to tell and not tell. When asked about a story he might know about his mother's childhood, William says, "I don't know the details . . . she doesn't really talk about her child life." In fact, it was his father who told William that his mother was adopted, and when asked why he thinks he was told, William responded that he "used to rip my brothers out about being adopted" and that his father did not want him to do this in front of his mother, because "it was rude," explaining that "when you rip people out about being adopted you're saying it's a bad thing." Across this interview, William expresses that he more or less grew up knowing his mother was adopted, and it was his father who told him at least initially. The source of the other vague details William has about his mother's history is less clear. But he also says that he never asked his mother anything about her life, so it is not clear whether his mother was secretive or simply responding to William's lack of interest. A theme that comes through in the interview is that William's father wants William to be careful about talking about this in front of his mother in the context of admonishing William more broadly for using "being adopted" as an insult.

William's narrative raises the question of how family secrets may emerge interactionally. Secrets emerge within family communications that are bidirectional. Five (of eight) of the adolescents who divulged some form of family secret indicated they knew because they asked, often persistently. The telling and not telling of family stories more broadly, and family secrets in particular, emerges in conversational interactions in which both partners are involved and interested in telling and hearing the stories. If parents are reluctant to tell and/or children are uninterested in hearing, the stories break down. William both knew and did not know about his mother being adopted, in the sense that this was something he was told early in childhood, but was never elaborated and it was at least minimally communicated that it was a difficult topic and perhaps should be avoided. That we as coders could not agree on whether this was a family secret or not indicates that William was himself unclear in communicating if and how this event was communicated about within the family. This lack of clarity might very well result in loss of family history across the generations.

\section{Emerging Themes and Implications}

Close examination of the ways in which New Zealand European adolescents express collusion, confusion, and whole-family secrets in telling intergenerational narratives both confirms and reveals ways in which family secrets are constructed through everyday family storytelling. Several critical observations emerged. First, even in a community sample, where adolescents were given no prompts about family secrets, about 10 percent of adolescents selected to provide such a narrative to an unknown interviewer. This is a substantial minority of adolescents interviewed, and

Journal of New Zealand Studies NS29 (2019), 20-36 https://doi.org/10.26686/jnzs.v0iNS29.6259 
suggests that these kinds of stories are reasonably frequent and also important to adolescents in making sense of their family history and of their own lives. It is possible that these adolescents will hear more stories of family secrets as they grow to adulthood and more of these events are divulged.

Our analysis further reveals the complexity of how family secrets may be told and not told simultaneously. The various ways in which adolescents expressed secretive practices around family history complicates the very idea of "family secrets." In some sense, none of these are secrets in that they are revealed, at least in some measure to some people. As mentioned, there very well may be real family secrets, things that are literally never mentioned, but what we discovered here is that there are many family experiences that are "secretive" if not exactly secrets.

Most of the within-family secretive narratives involved explicit collusion; one family member tells the adolescent about a difficult history and the adolescent narrates a sense that they are not to talk about it within the family. Most of these were one parent colluding with the adolescent about the other parent, often in the guise of protecting the other parent's feelings, or helping the child understand a difficult current parent-child relationship. But this is dangerous ground, especially for adolescents. Engaging in this kind of collusion can create unhealthy alliances and communication patterns and will not facilitate the adolescent's development of healthy adult relationships. Only two narratives were whole-family secrets and these were told by two sisters within one family, who told this story in very different ways, again pointing to the complexity of family secrets. That all of these narratives express ways in which stories are told and not told, told to certain people and not others, known by some but not all, point to the fact that family secrets are often not secrets at all, but forms of privileged knowledge within families. This kind of telling and not telling, knowing and not knowing, suggests a form of fragmentation that will likely make it difficult for these experiences to be communicated across the generations in ways that provide a coherent and cohesive family history. Even William's narrative, regarding which the coders could not agree on what was known when and by whom, indicates some form of fragmentation.

Only two adolescents expressed serious confusions and incoherence and this may not even reflect secrecy so much as the parents' own incoherence and confusions. Unlike collusion, which is explicit and clear about keeping secrets, confusion is more about lack of clarity about exactly what happened when and to whom, and seems to reflect more about the confused ways in which family history is being passed on than about silence. This level of confusion and incoherence is likely an index of family communication more broadly, possibly leading to poorer outcomes for the adolescent. Certainly, it will be difficult to pass on family history to the next generations when the stories are this confused and incoherent.

We were also somewhat surprised to discover that many traumatic events were not family secrets in any sense. Detailed stories about parental death, serious accidents, and wartime challenges were told by another 13 percent of these adolescents. These data suggest that, within some families, traumatic events are discussed openly whereas in others they may become nebulous family secrets, and of course in many families they may never be told at all. Future analyses would benefit from a more nuanced approach to what is told, what is not told and, perhaps most interesting, what is both told and not told simultaneously. These are critical questions both about preserving family

Journal of New Zealand Studies NS29 (2019), 20-36 https://doi.org/10.26686/jnzs.v0iNS29.6259 
history but also about creating family bonds. When families share difficult and challenging experiences, it may build positive bonds and a sense of personal and family resilience.

Finally, we note that girls told these kinds of narratives more frequently than boys, confirming previous research that women are the keepers of family history. This pattern extends previous findings that women are the keepers of family history in intriguing ways ${ }^{46}$ suggesting that even in childhood, girls become entangled in family conversations about what should and should not be told about family history to a greater extent than are boys.

We end with a note of caution. As in any qualitative analysis, we cannot generalize widely. Some of the patterns we identified may be specific to this cultural niche at the particular time in New Zealand history as discussed at the beginning of the paper. And, of course, although we tried to be as objective as we could, our own histories and perspectives inform our reading of these transcripts in ways that may have foregrounded or backgrounded particular issues. Still, our major objective was to examine possible ways in which families do and do not communicate difficult histories to their adolescents. In doing so, we discovered that family secrets are both relatively frequent and communicated in complex ways. Although all families may have secrets, our patterns suggest that some kinds of secrets may be more common than others; that different forms of family secrets may impact family history in different ways; and that women may be the keepers of family secrets to a greater extent than men.

Acknowledgments: We are grateful to the adolescents who participated in this research and who so generously shared their stories. We also thank Sarah-Jane Robertson for her assistance with transcription and project management. This research was funded by a grant from the Marsden Fund of the Royal Society of New Zealand to Elaine Reese.

\footnotetext{
${ }^{1}$ Annette Kuhn, Family Secrets: Acts of Memory and Imagination, new edition (New York: Verso, 2002), 2; Carol Smart, "Families, Secrets and Memories," Sociology 45, no. 4 (2011): 549.

2 Janet Finch, "Displaying Families," Sociology 41, no. 1 (2007): 65-66; Robyn Fivush, Family Narratives and the Development of an Autobiographical Self: Social and Cultural Perspectives on Autobiographical Memory (New York: Routledge, 2019), 25; David Morgan, Rethinking Family Practices (New York: Springer, 2011) 178

${ }^{3}$ Smart, "Families, Secrets and Memories," 549.

${ }^{4}$ Barbara Brookes, A History of New Zealand Women (Wellington: Bridget Williams Books, 2016), 297327.

${ }^{5}$ Brookes, 337-46.

${ }^{6}$ Barbara H. Fiese, Karen A. Hooker, Lisa Kotary, and Janet Schwagler. "Family Rituals in the Early Stages of Parenthood," Journal of Marriage and the Family (1993): 633.

${ }^{7}$ Robyn Fivush and Natalie Merrill, "An Ecological Systems Approach to Family Narratives," Memory Studies 9, no. 3 (2016): 307.

${ }^{8}$ Jennifer G. Bohanek, Robyn Fivush, Widaad Zaman, Caitlin E. Lepore, Shela Merchant, and Marshall P. Duke, "Narrative Interaction in Family Dinnertime Conversations," Merrill-Palmer Quarterly 55, no. 4 (2009): 505.
} 
${ }^{9}$ Dorthe Kirkegaard Thomsen and David B. Pillemer, "I Know my Story and I Know your Story: Developing a Conceptual Framework for Vicarious Life Stories," Journal of Personality 85, no. 4 (2017): 474-75.

${ }^{10}$ J. Assmann and J. Czaplicka, "Collective Memory and Cultural Identity," New German Critique (65): 126.

${ }^{11}$ Morgan, Rethinking Family Practices, 11-12; Elaine Reese and Robyn Fivush, "The Development of Collective Remembering," Memory 16, no. 3 (2008): 202.

${ }^{12}$ Yan Chen, Ella Cullen, Robyn Fivush, and Elaine Reese, "Mother, Father, and I: A Cross-Cultural Investigation of Adolescents' Intergenerational Stories and Well-Being," manuscript in preparation; Robyn Fivush, Jennifer G. Bohanek, and Widaad Zaman, "Personal and Intergenerational Narratives in Relation to Adolescents' Well-Being," New Directions for Child and Adolescent Development 2011, no. 131 (2011): 50; Natalie Merrill, Etasha Srinivas, and Robyn Fivush, "Personal and Intergenerational Narratives of Transgression and Pride in Emerging Adulthood: Links to Gender and Well-

Being," Applied Cognitive Psychology 31, no. 2 (2017): 124; see Fivush, Family Narratives, for a review.

${ }^{13}$ Natalie Merrill and Robyn Fivush, "Intergenerational Narratives and Identity across Development,"

Developmental Review 40 (2016): 78.

${ }^{14}$ Morgan, Rethinking Family Practices, 172-73.

${ }^{15}$ Morgan, 135.

${ }^{16}$ Kuhn, Family Secrets, 1; Margaret McNay, “Absent Memory, Family Secrets, Narrative Inheritance," Qualitative Inquiry 15, no. 7 (2009): 1186; Smart, "Families, Secrets and Memories," 540.

${ }^{17}$ Marshall P. Duke, Amber Lazarus, and Robyn Fivush, "Knowledge of Family History as a Clinically Useful Index of Psychological Well-Being and Prognosis: A Brief Report," Psychotherapy: Theory, Research, Practice, Training 45, no. 2 (2008): 269; Kelly A. Marin, Jennifer G. Bohanek, and Robyn Fivush, "Positive Effects of Talking about the Negative: Family Narratives of Negative Experiences and Preadolescents' Perceived Competence," Journal of Research on Adolescence 18, no. 3 (2008): 586.

${ }^{18}$ Duke, Lazarus, and Fivush, "Knowledge of Family History," 270.

${ }^{19}$ Anita L. Vangelisti, "Family Secrets: Forms, Functions and Correlates," Journal of Social and Personal Relationships 11, no. 1 (1994): 115.

${ }^{20}$ Ashley Barnwell, "Hidden Heirlooms: Keeping Family Secrets across Generations," Journal of Sociology 54, no. 3 (2018): 448.

${ }^{21}$ Morgan, Rethinking Family Practices, 40.

22 Jimmie Manning, "Families Living in Closets: Talking about Alcoholism in and out of Family Households," Contemporary Case Studies in Health Communication (2015): 162.

${ }^{23}$ Vangelisti, "Family Secrets," 119-20; Anita L Vangelisti and John P. Caughlin, "Revealing Family Secrets: The Influence of Topic, Function, and Relationships," Journal of Social and Personal Relationships 14, no. 5 (1997): 679.

${ }^{24}$ Manning, "Families Living in Closets," 162.

${ }^{25}$ Barnwell, "Hidden Heirlooms," 449.

${ }^{26}$ Harald Welzer, Sabine Moller, Karoline Tschuggnall, Olaf Jensen, and Torsten Koch, "From 'Grandpa Wasn't a Nazi: National Socialism and Holocaust in Family Memory,'“ in The Collective Memory

Reader, ed. Jeffrey K. Olick, Vered Vinitzky-Seroussi, and Daniel Levy (Oxford: Oxford University Press, 2005): 344.

${ }^{27}$ Harold L. Goodall, Jr, "Narrative Inheritance: A Nuclear Family with Toxic Secrets," Qualitative Inquiry 11, no. 4 (2005): 495.

${ }^{28}$ McNay, "Absent Memory," 5.

${ }^{29}$ Clare de Lore, “Acclaimed Writer Greg McGee on his Family's Stolen Children.” Stuff.co.nz. https://www.stuff.co.nz/entertainment/books/114283353/acclaimed-writer-greg-mcgee-on-his-familysstolen-children

${ }^{30}$ Brookes, A History of New Zealand Women, 297.

Journal of New Zealand Studies NS29 (2019), 20-36 https://doi.org/10.26686/jnzs.v0iNS29.6259 
31 “The Life Story Interview," Foley Center for the Study of Lives, available at https://www.sesp.northwestern.edu/foley/instruments/interview/

32 Jacqueline Smollar and James Youniss, "Transformations in Adolescents' Perceptions of Parents," International Journal of Behavioral Development 12, no. 1 (1989): 79-80.

${ }^{33}$ Elaine Reese, Robyn Fivush, Natalie Merrill, Qi Wang, and Helena McAnally, "Adolescents' Intergenerational Narratives across Cultures," Developmental Psychology 53, no. 6 (2017): Table 5.

${ }^{34}$ See Fivush, Family Narratives, for an overview of this research.

${ }^{35}$ Elaine Reese and Robyn Fivush, "The Development of Collective Remembering," Memory 16, no. 3 (2008): 203-04.

${ }^{36}$ Anna Green, "Individual Remembering and 'Collective Memory': Theoretical Presuppositions and Contemporary Debates," Oral History 32, no. 2 (2004): 40.

${ }^{37}$ Heather Fraser, "Doing Narrative Research: Analysing Personal Stories Line by Line," Qualitative Social Work 3, no. 2 (2004): 183-84.

${ }^{38}$ Ruthellen Josselson, "'Bet You Think this Song is about You': Whose Narrative is it in Narrative Research?" Narrative Works 1, no. 1 (2011), 37.

${ }^{39}$ Rachel Lev-Wiesel, "Intergenerational Transmission of Trauma across Three Generations: A Preliminary Study," Qualitative Social Work 6, no. 1 (2007): 77.

${ }^{40}$ Merrill, Srinivas, and Fivush, "Personal and Intergenerational Narratives of Transgression," 125; Widaad Zaman and Robyn Fivush. "When my Mom was a Little Girl . . .: Gender Differences in Adolescents' Intergenerational and Personal Stories," Journal of Research on Adolescence 21, no. 3 (2011): 711.

${ }^{41}$ Barnwell, "Hidden Heirlooms," 454.

${ }^{42}$ See Fivush, Family Narratives, for a review.

${ }^{43}$ Zaman and Fivush, "When my Mom was a Little Girl," 710.

${ }^{44}$ Theodore E. A. Waters and Robyn Fivush, "Relations between Narrative Coherence, Identity, and Psychological Well-Being in Emerging Adulthood," Journal of Personality 83, no. 4 (2015): 446.

${ }^{45}$ Monisha Pasupathi and Timothy Hoyt, "The Development of Narrative Identity in Late Adolescence and Emergent Adulthood: The Continued Importance of Listeners," Developmental Psychology 45, no. 2 (2009): 560.

${ }^{46}$ Carolyn J. Rosenthal, "Kinkeeping in the Familial Division of Labor," Journal of Marriage and the Family (1985): 973. 